\title{
Messad / Castellum Dimmidi (Antiquité)
}

\section{P. Trousset}

\section{OpenEdition}

Journals

Édition électronique

URL : http://journals.openedition.org/encyclopedieberbere/571

DOI : 10.4000/encyclopedieberbere.571

ISSN : 2262-7197

\section{Éditeur}

Peeters Publishers

\section{Édition imprimée}

Date de publication : 30 décembre 2010

Pagination : 4898-4902

ISBN : 978-90-429-2368-3

ISSN : 1015-7344

\section{Référence électronique}

P. Trousset, « Messad / Castellum Dimmidi (Antiquité) », Encyclopédie berbère [En ligne], 31 | 2010, document M95b, mis en ligne le 08 octobre 2020, consulté le 12 octobre 2020. URL : http:// journals.openedition.org/encyclopedieberbere/571; DOI : https://doi.org/10.4000/ encyclopedieberbere.571

Ce document a été généré automatiquement le 12 octobre 2020.

(c) Tous droits réservés 


\title{
Messad / Castellum Dimmidi (Antiquité)
}

\author{
P. Trousset
}

Cet avant-poste, le plus méridional du système frontalier du limes de Numidie, est situé à quelque $350 \mathrm{~km}$ au Sud-Ouest de Lambèse, dans le pré-désert algérien, sur un des derniers chaînons méridionaux de l'Atlas saharien. Ses vestiges qui ont fait l'objet d'une étude approfondie de G.-Ch. Picard entre 1939 et 1947, se trouvaient dans le Djebel Bou Kahil, sur une butte gréseuse riche en salpêtre et désignée pour cette raison sous le nom de Ksar el-Baroud. Le fort romain occupait une position stratégique remarquable à un carrefour de pistes lui permettant de surveiller à la fois les monts des Ouled Naïl et la vallée de l'oued Djedi (le Flumen Nigris des Anciens). Bien que la localité actuelle la plus proche soit celle de Messad, un autre village plus ancien du nom de Demmed avait gardé presque inchangé celui dérivé du libyque de castellum Dimmidi. L'origine berbère du toponyme soulignée déjà par E. Albertini, s'inscrivait pour $\mathrm{J}$. Carcopino dans une série de noms dont la terminaison en di échappait aux flexions de la déclinaison latine. "Comme Thamugadi devenu Timgad, Dimmidi a gardé intacte, pendant dix-sept siècles sa dentale terminale - seule l'apocope de la voyelle en a altéré légèrement le nom, sans en modifier d'ailleurs beaucoup la prononciation » (Picard, p. 31). La butte du Ksar faisant fonction d'éperon barré offrait des vues étendues sur les pistes conduisant à Laghouat et contrôlait ainsi un couloir de circulation essentiel entre cette oasis et le bassin du Hodna ainsi que les défilés à travers les escarpements montagneux entre l'oued Djedi et Djelfa. On a donc tout lieu de penser qu'il avait pu faire l'objet d'une occupation préromaine par une population gétule* et peut-être même, selon G.-Ch. Picard, servir de lieu de culte car il était pourvu d'un point d'eau inclus ultérieurement dans un petit temple des principia du fortin romain. Les sépultures nombreuses (du type bazina*) et plus encore les gravures rupestres recensées notamment dans le bassin de l'oued Itel témoignent, au demeurant, d'une occupation des plus anciennes de toute cette région présaharienne.

2 Avant même les fouilles entreprises sur le site, toute une série d'inscriptions latines avaient été signalées et répertoriées dans l'Atlas de St. Gsell (A.A., feuille 47, Aïn Rich, 
site 23). Avec les autres textes découverts au cours des dégagements des ruines, notamment la dédicace des principia du camp (Picard, p. 188, $\mathrm{n}^{\circ} 12, A E 1948,214$ ), on pouvait établir avec une bonne précision l'histoire, assez brève puisqu'elle n'a duré que quarante ans, de cet avant-poste et surtout identifier les unités militaires qui y furent impliquées. Le castellum Dimmidi a été fondé en 198 sous le règne de Septime Sévère alors que Q. Anicius Faustus, souvent cité en d'autres lieux dans cette phase d'expansion maximale de la frontière d'Afrique, occupait le poste de légat propréteur de la III Légion Auguste à Lambèse. La construction de la forteresse été exécutée par un détachement comprenant deux vexillations de la IIIa Augusta et de la IIIa Gallica - un corps stationné en Syrie -, elles-mêmes protégées par des cavaliers de la I ère Aile des Pannoniens dont le préfet, Flavius Superus, assurait le commandement de l'ensemble de la colonne venue sans doute par El Gahra et Aïn Rich. Par la suite, le poste n'aurait été occupé que par une garnison de légionnaires de l'armée d'Afrique, de 198 à 225 et de 235 à 238 ; bien que ceux-ci eussent été renforcés sous le règne de Sévère Alexandre pendant les années 226 à 235 par les hommes du numerus de Palmyréniens et de l'Aile Flavienne, la garnison n'a jamais dû compter que 70 à 90 hommes si l'on en juge par la dimension des casernements. Enfin le site a été évacué en 238, peu avant la dissolution de la III Légion - car les inscriptions qui la mentionnent n'y ont pas été martelées sous le règne de Gordien III (Picard, p. 119). L'abandon sans retour de cette antenne saharienne marque un premier repli significatif du système frontalier romain. Outre le détachement des légionnaires de la IIIa Augusta, l'unité la plus fréquemment citée par les textes et qui a le plus marqué l'avant-poste de son empreinte est bien le numerus Palmyrenorum, dont le quartier général devait se trouver à El Kantara (Le Bohec 1989, 2, p. 122). On admet en général que ces militaires avaient été installés dans la région en raison de leur expérience du désert et de ses populations nomades: archers très mobiles, ils servaient de troupes légères aux patrouilles pour prévenir les attaques surprises et surveiller les déplacements saisonniers des éleveurs sahariens en direction $\mathrm{du}$ Tell. Bien qu'ils soient restés fidèles à leurs croyances orientales - comme le montre en particulier leur culte au dieu Malagdel dans la salle des fresques - les épitaphes révèlent néanmoins une romanisation progressive de ces soldats Palmyréniens. 


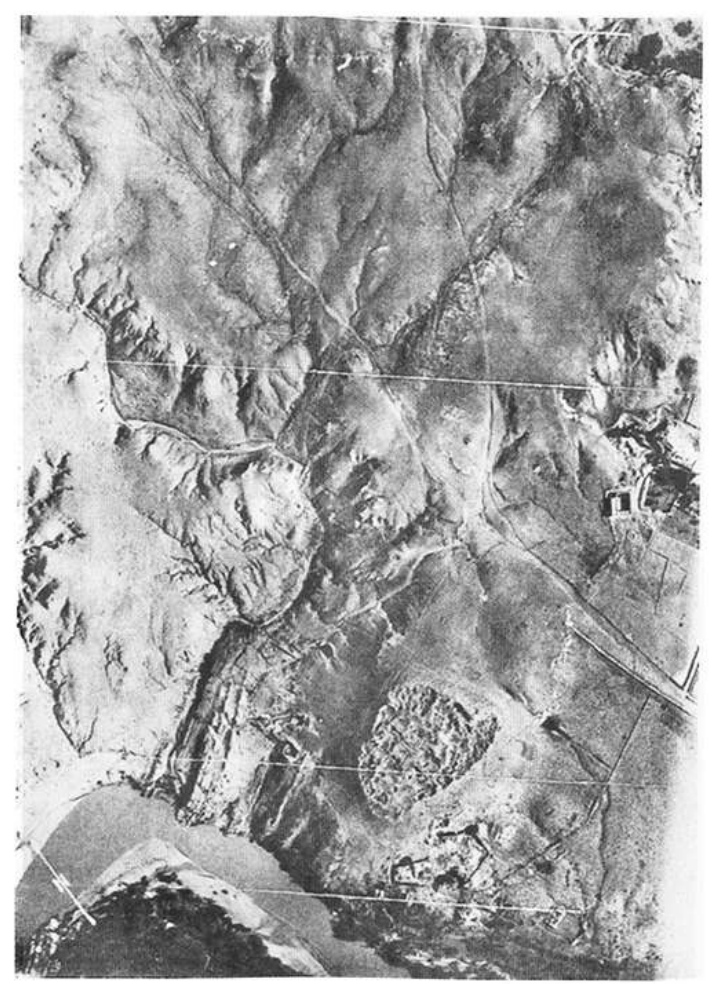

LE « KSAR EL BAROUD » (D'APRÈS PICARD PL. 1)

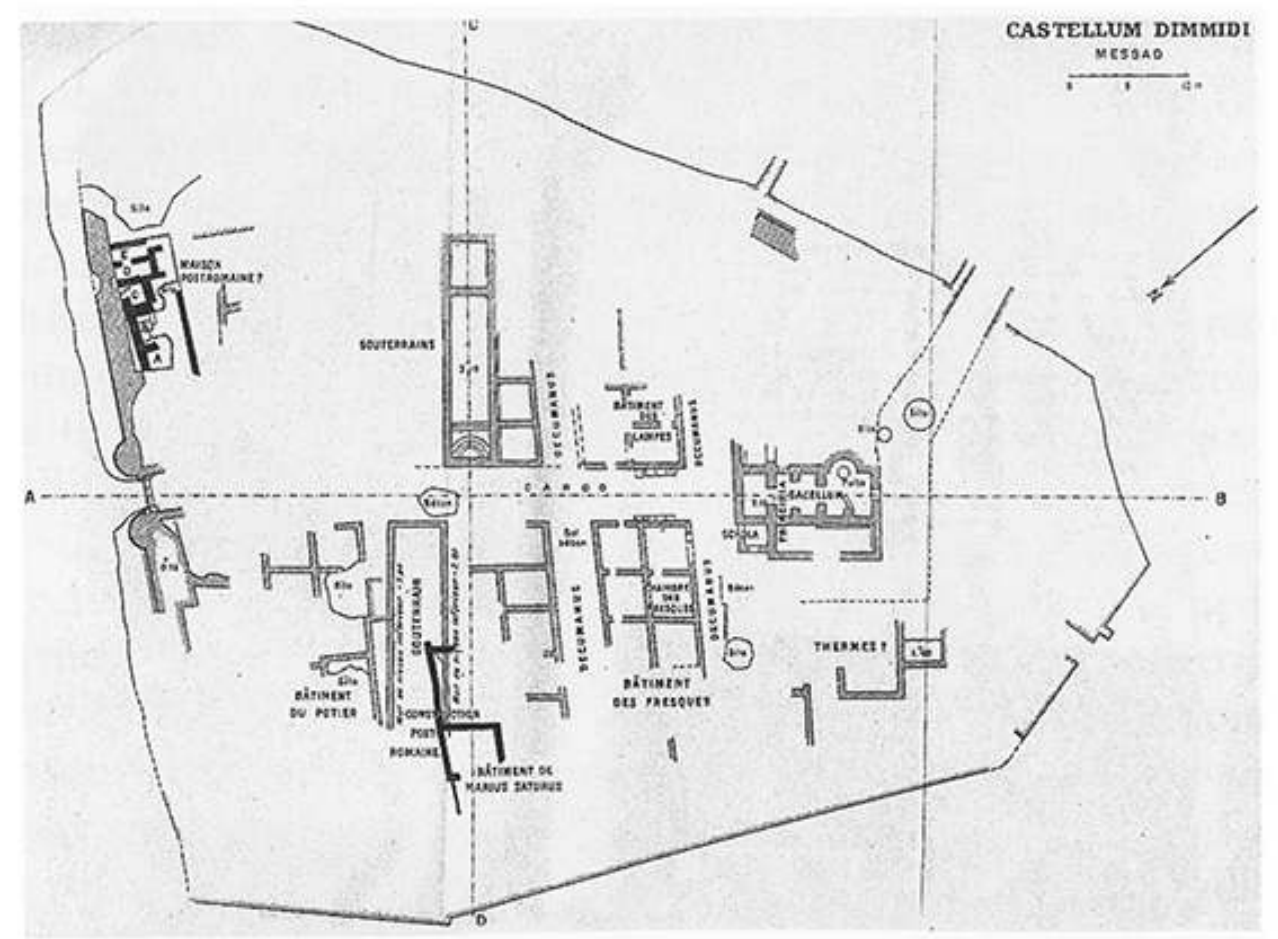

PLAN DU CASTELLUM DIMMIDI (D'APRÈS PICARD, fig. 1)

3 L'ouvrage fortifié lui-même est de superficie réduite (moins d'un hectare) et il présente une enceinte dont la forme atypique a du tenir compte de la topographie inégale de la butte. Le mur opus incertum enserrant un blocage de terre atteint $2 \mathrm{~m}$ de large ; sur la face la plus rectiligne tournée au Nord-Ouest, s'ouvrait une porte à couloir flanquée de 
deux tours demi-rondes. À l'intérieur l'ordonnancement des casernements et des magasins (en partie souterrains) est en revanche plus classique et s'organise le long d'axes perpendiculaires, l'un d'eux, le cardo, conduisant de l'entrée aux principia. Ces derniers ont fait l'objet des premiers dégagements des fouilleurs, révélant l'existence d'un petit temple sur podium d'un type original. Ce bâtiment qui correspond au praetorium avait une cave où se trouvait le puits déjà mentionné et où ont été découverts des objets rituels dont un autel cinéraire et une stèle portant les attributs de Caelestis. Pour G.-Ch. Picard, il s'agirait de survivances religieuses africaines. Parmi les témoins des cultes militaires attestés dans ce sanctuaire figurent les autels et dédicaces à Juppiter Conservator ; une stèle sculptée anépigraphe atteste la célébration à Dimmidi du culte du Juppiter Dolichenus, ce Baal syrien élevé à Lambèse au rang de patron semi officiel de l'armée romaine. Plus énigmatique parmi ces cultes officiels est la cérémonie saisonnière de l'ara Cerei célébrée le 3 mai et qui pourrait marquer la fin des Floralies. Enfin au milieu des casernements disposés per strigas le long des allées décumanes et divisées en chambrées régulières de 150 pieds carrés $(3,60 \times 3,60 \mathrm{~m})$, une place de choix doit être faite à la "chambre des fresques", sanctuaire des Palmyréniens. À partir des débris de plâtre qui portaient des traces de plusieurs décors peints successifs, des portraits ont pu être restitués, conformes à des modèles connus à Doura Europos et dont l'un a été identifié par G.-Ch. Picard comme pouvant être celui du dieu solaire de Malagdel, protecteur préféré des Palmyréniens d'Occident.

D'autres traces relevées dans les ruines du Ksar el-Baroud se rapportent à une occupation berbère postérieure à l'évacuation du castellum par les Romains en 238 . Il s'agit de murs dont le tracé recoupe irrégulièrement le tracé des constructions antérieures. D'après le matériel recueilli en particulier des meules à grain et des ossements d'animaux, on peut penser que le site a été réutilisé par les populations locales à la manière des Ksours, comme silos ou enclos fortifié pour la protection des récoltes et des troupeaux. 


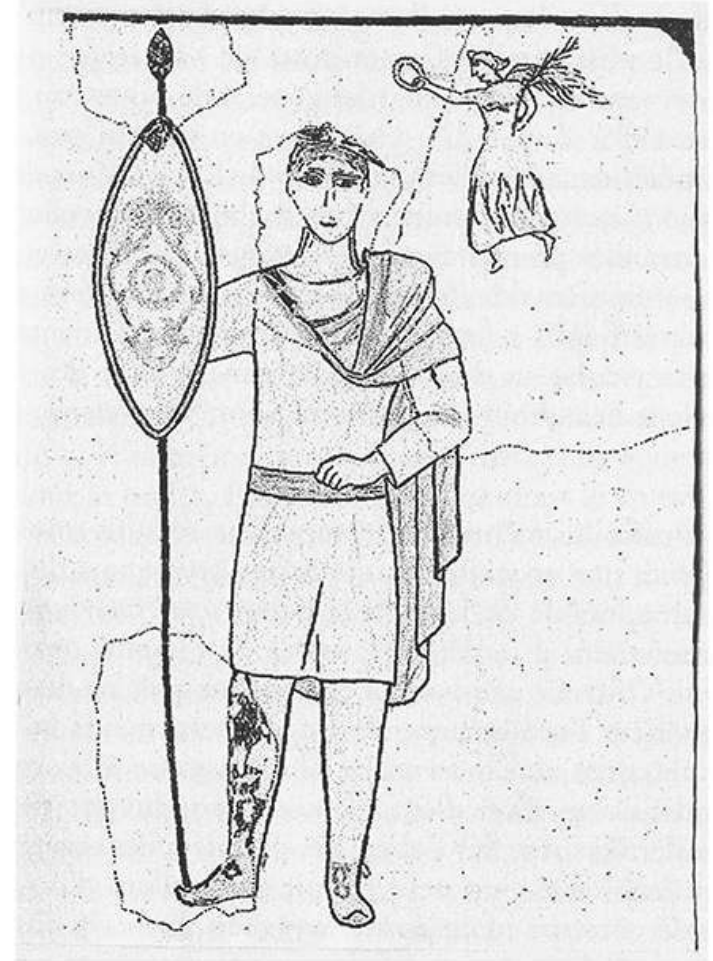

FResque ReConstituer du dieu MALAgDel (SELA PiCARD P. 163, fig. 15)

\section{BIBLIOGRAPHIE}

PICARD G.-Ch., Castellum Dimmidi, Alger, Paris, 1947.

FENTRESS E. W. B., Numidia and the Roman Army, B.A.R. Intern. Ser., 53, 1979 p. 87, 103.

LE BOHEC Y., La Troisième Légion Auguste, éd. CNRS, Paris, 1989, p. 435-437.

LE BOHEC Y. Les unités auxiliaires de l'armée romaine en Afrique Proconsulaire et Numidie sous le Haut Empire, éd. CNRS, 1989, p. 120-140.

INDEX

Mots-clés : Antiquité, Romain, Rome 